\title{
Evolution of Porosity Profiles of Magnetite Phase during High Temperature Reduction of Hematite
}

\section{J. JANOWSKI, A. BARAŃSKI ${ }^{1)}$ and A. SADOWSKI}

Faculty of Metallurgy and Material Science, University of Mining and Metallurgy, PL 30-059 Cracow, Poland.

1) Regional Laboratory of Physicochemical Analyses and Structural Research, Jagiellonian University, PL 30-060 Cracow, Poland.

(Received on June 15, 1995; accepted in final form on September 25, 1995)

\begin{abstract}
The reduction of initially nonporous hematite to porous magnetite by $\mathrm{CO}+\mathrm{CO}_{2}(3: 97)$ mixture was monitored thermogravimetrically at $850^{\circ} \mathrm{C}$. For the series of six kinetic runs the grains of diameter ca. $1.5 \mathrm{~mm}$ were used. The final reduction degree varied from 13 to $100 \%$. After each kinetic run the microscopic observations of the central cross-section of grains were done in quantitative way. The observations yielded the values of local porosity. The empirical equations were found describing the continuous exponential decrease of local porosity with the distance from the external surface of the grain. The value of total porosity obtained by mercury porosimetry agrees in a reasonable way with microscopic data.

The classical shrinking core model (SCM) was fitted to kinetic data. The model took into account the gas-solid reaction occurring at sharp defined interface as well as the pore diffusion phenomena occurring inside the magnetite layer. The model was also modified. The local value of porosity was introduced to the definition of effective diffusivity $\left(D^{\text {eff }}\right)$. In this way $D^{\text {eff }}$ was allowed to vary with the distance from the external surface of the grain. The corrected three parameter SCM yielded slightly worse results. It implies that apart from the spatial variation of $D^{\text {eff }}$ the temporal one should be also considered. Indeed, it was found that the local porosity of the already reduced layer varied also with time. However, the data are not accurate enough to permit the temporal variation of $D^{\text {eff }}$ to be included in the model calculation.
\end{abstract}

KEY WORDS: hematite; magnetite; reduction; shrinking core model; effective diffusivity.

\section{Introduction}

At present the limitations of the concept of the rate determining step are widely recognized and the assumption of mixed-control became state-in-art requirement for kinetic models of gas solid reactions. ${ }^{1)}$ This implies that effective diffusivity ( $D^{\text {eff }}$ ) appears to be the parameter of kinetic equation obtained by fitting models to experimental data. Usually, for a single phase only one value of $D^{\text {eff }}$ is used. If the kinetic equation is considered to be only an empirical relation one can say that effective diffusivity characterizes the properties of a given phase in an averaged way. However, if the physicochemical meaning of a kinetic equation is considered, the uniformity of properties (porosity, tortuosity factor, pore distribution) throughout the phase is the obvious justification for a single value of $D^{\text {eff }}$.

The assumption of the uniformity of properties is unrealistic in the case of a complete gasification of solids when pore structure changes in a continuous way with space and time. This is why attempts had been undertaken to experimentally determine the porosity profiles. ${ }^{2)}$ The profiles reveal the relation between the porosity and the distance from the surface of solid. This means that the local values of porosity are known and hence the local values of effective diffusivities can be calculated under the more or less reasonable assumption concerning e.g. the uniformity of values of tortuosity factor.

Now, let us focus our attention on the reactions of type:

$$
\text { porous solid } 1+\text { gas }_{A} \rightarrow \text { porous solid } 2+\operatorname{gas}_{B}
$$

As pointed out by Szekely" 'the diffusivity will, in general, change with the degree of local conversion of the solid reactant.' This statement is based on the tacit assumption of the existence of porosity profiles. In this context two diffusivity model by Ishida and Wen ${ }^{4)}$ should be mentioned, as well as the concept of Matyas and Bradshaw ${ }^{5)}$ concerning the variation of diffusion coefficients 'from a lower value at the beginning of the run to a higher value at the end.' Also model considerations may yield a prediction concerning porosity profiles. For example, the use of crackling core model by Park and Levenspiel ${ }^{6)}$ directly implies in a general case the existence of porosity gradients inside the solid grain. The existence of profiles can be also inferred from the studies concerning the reduction of iron catalyst, i.e. promoted magnetite. ${ }^{7)}$ However, this hypothesis was never tested by quantitative microscopic observations.

Taking into account the examples outlined above one can conclude that the concept of porosity profiles seems to be useful and it implies the need of an experimental 
verification. It seems obvious that the verification starting with the simplest case of shrinking core-and-shell behaviour of nonporous solid is the proper way to tackle this matter. The case may be exemplified by technologically important case of reduction of hematite. From the review paper, ${ }^{8)}$ fundamental data ${ }^{9)}$ and our own recent studies $^{10)}$ it is known that the mode of hematite reduction, namely the crackling mode, the topochemical mode or inner whiskers mode depend on temperature, gas phase composition and crystal size. For experimental conditions chosen in this study, as described below, topochemical behaviour was undoubtedly observed where a nonporous hematite core was surrounded by a porous magnetite shell.

\section{Experimental}

\subsection{Sample}

For these studies the crystalline natural hematite (specularite) from Mines Gerais, Brazil, was chosen. Total amount of impurities did not exceed $0.5 \%$. The results of atomic absorption spectroscopy analyses are listed in Table 1. The hematite sample was crushed and sphere-like grains of the dimensions of about $1.5 \mathrm{~mm}$ were selected for the studies. Jutting corners of the grains were cut off in order to correct the shape.

\subsection{Thermogravimetry}

Selected sphere-like grains were used for kinetic experiments. Basic series consists of 6 runs denoted $\mathrm{H}-\mathrm{I}$ to H-VI. The aim was to get samples revealing the variable final reduction extent. For each run 5 grains were used. The dimension of each grain was meaured by slide caliper several times with the accuracy of $0,1 \mathrm{~mm}$. A half of the averaged dimensions for all 5 grains called the kinetic radius $\left(r_{\mathrm{k}}\right)$, was used for kinetic calculations (see Table 2).

The reduction of hematite to magnetite was monitored

Table 1. Contents of impurities in specularite sample.

\begin{tabular}{cccccccc}
\hline \multicolumn{7}{c}{ Impurities $(w t \% \cdot 100)$} \\
& $\mathrm{Ca}$ & $\mathrm{Si}$ & $\mathrm{Al}$ & $\mathrm{Ti}$ & $\mathrm{Mn}$ & $\mathrm{K}$ \\
\hline $\mathrm{I}$ & 2 & 17 & 3 & 8 & 0.4 & 9 \\
\hline
\end{tabular}

thermogravimetrically in Mettler TA-1 apparatus. Its reaction chamber of the volume of ca. $0.3 \mathrm{dm}^{3}$ cannot be considered as a tubular reactor. The grains were heated in $\mathrm{CO}_{2}$ up to $850^{\circ} \mathrm{C}$. Then the already prepared mixture $\mathrm{CO}+\mathrm{CO}_{2}(3: 97)$ was introduced. The gas flow $35 \mathrm{~N} l / \mathrm{h}$ at atmospheric pressure was constant. The rate of $\mathrm{CO}$ supply exceed the maximal reduction rate by three orders of magnitude. In the preliminary experiments it was shown that within the gas flow range from 20 to $35 \mathrm{~N} l / \mathrm{h}$ the reduction rate does not depend on the flow. No analysis concerning gas film diffusion-as done in noteworthy paper by Ohmi et $a .^{11)}$ — was made in this study.

The mass decrease was recorded until the assumed reduction degree $(R)$ was attained. The reduction degree was defined as the ratio of oxygen removed to the removable oxygen. The correction for impurities content was not taken into account. The first change of the mass seen on gravimetric kinetic curve was taken as the beginning of the experiment $(t=0)$. During the initial period of reduction due to-at least-the increase of $\mathrm{CO}$ concentration around the sample the reduction rate increased.

\subsection{Microscopy}

A single grain from each run was taken for microscopic observations using the image analyzer Pericolor 2000. The grain was embedded in Citofix (Struers) resin. In order to get the central cross-section the grain was grounded and polished by diamond paste of continuously decreasing dispersion until $0.25 \mu \mathrm{m}$ paste was finally used. Then the grain was washed and dried.

The dimensions of cross-section were measured using a microscope. The mean dimension was calculated as an arithmetic mean of maximal and minimal dimensions. Half of the microscope dimension is simply called radius $\left(r_{\mathrm{m}}\right)$ (see Table 2). The scheme of the cross-section of the grain is presented on Fig. 1. It consists of a hematite core surrounded by a magnetite shell. Within the shell a number of zones was chosen. Every zone was divided into slices numbered $1,2, \cdots, i \cdots, j$. The slices stick each to other. Their maximal number in a given zone was $j$. For a given grain the fixed value of slice thickness $(d)$ was chosen identical for all slices in every zone. The thickness of magnetite shell was approximated by:

Table 2. Characterization of the grains.

\begin{tabular}{|c|c|c|c|c|c|c|c|c|c|c|c|c|c|}
\hline \multirow[t]{3}{*}{ Exp.No. } & \multirow[t]{2}{*}{$\begin{array}{l}\text { Kinetic } \\
\text { radius } r_{k}\end{array}$} & \multirow[t]{2}{*}{$\begin{array}{l}\text { Radius of } \\
\text { grain } r_{m}\end{array}$} & \multirow[t]{2}{*}{$\begin{array}{l}\text { Reduction } \\
\text { degree }\end{array}$} & \multicolumn{3}{|c|}{ Slice characterization } & \multicolumn{3}{|c|}{ Number of slices within a zone } & \multirow[t]{2}{*}{$\begin{array}{l}\text { Number } \\
\text { of zones }\end{array}$} & \multicolumn{3}{|c|}{$\begin{array}{l}\text { Relative layer thickness } \\
\text { of magnetite shell }\end{array}$} \\
\hline & & & & width & thickness & area & $\min$. & mean & $\max$. & & $\mathrm{d}_{\min } / \mathrm{r}_{\mathrm{m}}$ & $\mathrm{d}_{\text {mean }} / \mathrm{r}_{\mathrm{m}}$ & $\mathrm{d}_{\max } / \mathrm{r}_{\mathrm{m}}$ \\
\hline & $\mu \mathrm{m}$ & $\mu \mathrm{m}$ & $\%$ & $\mu \mathrm{m}$ & $\mu \mathrm{m}$ & $\mu \mathrm{m}^{2}$ & & & & & & & \\
\hline 1 & 2 & $\frac{1}{3}$ & 4 & 5 & 6 & $\frac{5 x}{7}$ & 8 & 9 & 10 & 11 & 13 & 14 & 15 \\
\hline $\mathrm{H}-\mathrm{I}$ & $760 \pm 50$ & $750 \pm 60$ & 13.2 & 225 & 4.9 & 1103 & 9 & 10.5 & 12 & 6 & 0.059 & 0.069 & 0.078 \\
\hline $\mathrm{H}-\mathrm{II}$ & $740 \pm 60$ & $725 \pm 35$ & 35.4 & 225 & 4.9 & 1103 & 17 & 19 & 21 & 6 & 0.115 & 0.128 & 0.142 \\
\hline $\mathrm{H}-\mathrm{III}$ & $750 \pm 80$ & $735 \pm 35$ & 60.3 & 225 & 9.8 & 2206 & 13 & 15.2 & 17 & 6 & 0.173 & 0.202 & 0.227 \\
\hline $\mathrm{H}-\mathrm{IV}$ & $770 \pm 80$ & $650 \pm 50$ & 84.0 & 225 & 9.8 & 2206 & 19 & 21.4 & 24 & 5 & 0.296 & 0.323 & 0.362 \\
\hline $\mathrm{H}-\mathrm{V}$ & $740 \pm 50$ & $703 \pm 37$ & 95.0 & 316.5 & 29.4 & 9305 & 12 & 14.2 & 16 & 5 & 0.501 & 0.594 & 0.669 \\
\hline $\mathrm{H}-\mathrm{VI}$ & $770 \pm 80$ & $853 \pm 3$ & 100 & 316.5 & 29.4 & 9305 & 28 & 28.8 & 29 & 4 & 1 & 1 & 1 \\
\hline
\end{tabular}




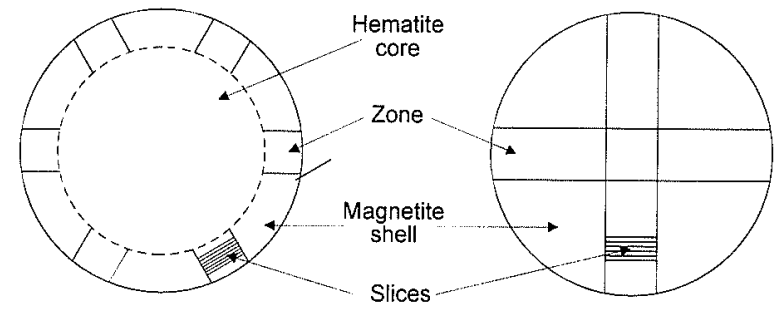

(a)

(b)

Fig. 1. Idealized scheme of the grain for reduction degree; (a) $60 \%$ and (b) $100 \%$.

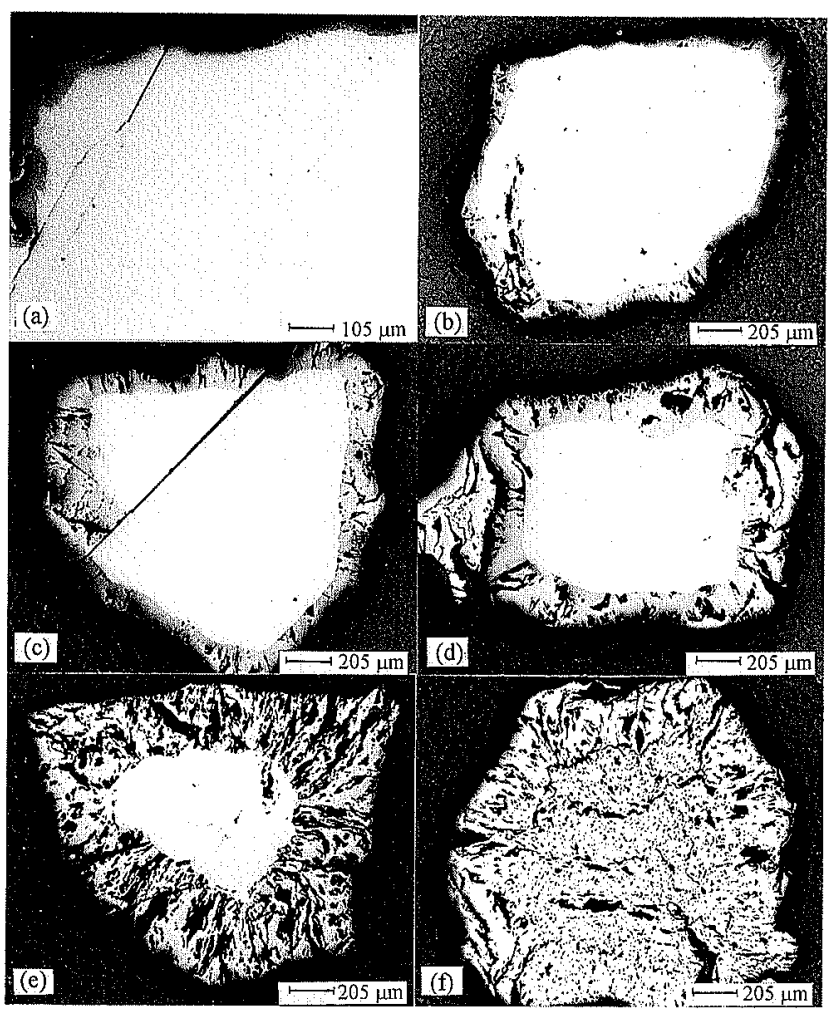

Fig. 2. Microphotographs of reduced grains. Reduction degrees: (a) $13 \%$, (b) $35 \%$, (c) $60 \%$, (d) $84 \%$, (e) $95 \%$ and (f) $100 \%$.

$$
\begin{aligned}
& d_{\min }=d \cdot j_{\min } \\
& d_{\text {mean }}=d \cdot j_{\text {mean }} \\
& d_{\text {max }}=d \cdot j_{\text {max }}
\end{aligned}
$$

where $j_{\text {min }}, j_{\text {mean }}$ and $j_{\max }$ are given in Table 2 .

Porosity within each slice $\left(P_{i}\right)$ was calculated as the ratio of area of pores seen as black to the total area of slice. Hematite and magnetite were seen as white and grey, respectively.

\subsection{Porosimetry}

Mercury porosimeter, Carlo Erba, model 2000 was used. High pressure (1-2000 atm) and low pressure (below $1 \mathrm{~atm}$ ) measurements were performed.

\section{Results}

\subsection{Microscopic Observations}

Typical cross sections of the grains are presented on Fig. 2. The following features of core and shell model are worthwhile mentioning: the sharp core-shell interphase, lack of pores inside core and lack of hematite inside shell. For the grain reduced only to $13 \%$ the already reduced layer was very thin and this is why only a part of the grain was shown in the greater magnification.

The quantitative characterization of the cross sections is given in Table 2 .

The determined values of porosity $\left(P_{i}\right)$ were plotted against dimensionless quantity $d_{i} / r_{\mathrm{m}}$ where $d_{i}=d \cdot i$ stands for thickness of magnetite layer consisting of $i$ slices. The porosity profiles are shown on Fig. 3.

Taking into account the overlapping of zones in the central part of the grain (Fig. 1(b)) one can conclude that in the case of the profile of the fully reduced sample the reliability of the last five points is doubtful. The quantitative implications of this fact were neglected.

Porosity profiles do not reveal any extreme and their slopes decrease monotonously with the increasing final reduction degree. This is why an effort was made to find an empirical equation describing the curves in question hoping that:

- the type of equation will be the same for all profiles,

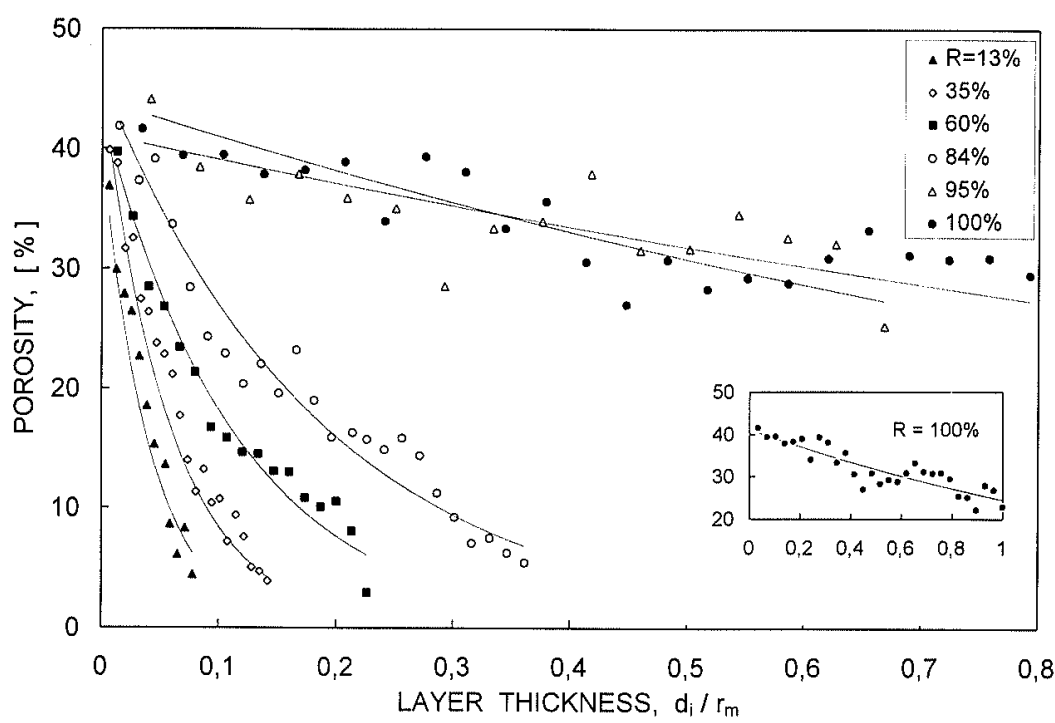

Fig. 3.

Porosity profiles of magnetite layer. Values of final reduction degrees are given in figure. 
Table 3. Plots of local porosity versus dimensionless distance from the external surface of grains.

\begin{tabular}{lccccc}
\hline Exp. No & $\begin{array}{c}\text { Final reduction } \\
\text { degree R (\%) }\end{array}$ & $\begin{array}{c}\text { Mean thickness of } \\
\text { reduced layer } d_{\text {mean }} / r_{\mathrm{m}}\end{array}$ & $P=f\left(d_{i} / r_{\mathrm{m}}\right)(\%)$ & $\begin{array}{c}\text { Correlation } \\
\text { coefficient }\end{array}$ & Remarks \\
\hline I & 2 & 3 & 4 & 5 \\
\hline H-I & 13.2 & 0.069 & $46.5 \exp \left(-23.8 d_{i} / r_{\mathrm{m}}\right)$ & 0.972 \\
H-II & 35.4 & 0.128 & $50.9 \exp \left(-16.9 d_{i} / r_{\mathrm{m}}\right)$ & 0.983 \\
H-III & 60.3 & 0.202 & $43.1 \exp \left(-8.65 d_{i} / r_{\mathrm{m}}\right)$ & 0.969 & 6.636 \\
H-IV & 84.0 & 0.323 & $45.6 \exp \left(-5.25 d_{i} / r_{\mathrm{m}}\right)$ & many cracks, \\
H-V & 95.0 & 0.594 & $44.0 \exp \left(-0.71 d_{i} / r_{\mathrm{m}}\right)$ & 0.881 expansion of the \\
H-VI & 100 & 1 & $41.2 \exp \left(-0.51 d_{i} / r_{\mathrm{m}}\right)$ & & sample \\
\hline
\end{tabular}

- the number of parameters will be low,

- the trend in the parameter values will be observed.

Standard minimization procedure was applied for these calculations.

Simple exponential relations between the local porosity values $\left(P_{i}\right)$ and dimensionless distance from the external surface of grain $\left(d_{i} / r_{\mathrm{m}}\right)$ are given in Table 3 . The preexponential term is perhaps constant, whereas the exponential term parameter decreases strongly with the increasing final reduction degree.

\subsection{Porosimeter Measurements}

In order to check the reliability of microscopic data, the porosity of the fully reduced sample H-VI was also determined by the mercury porosimetry. The porosity spectrum is shown on Fig. 4. A large peak at $0.6 \mu \mathrm{m}$ is visible, and the existence of local maxima at 0.15 and at $10 \mu \mathrm{m}$ can be inferred with a certain degree of probability.

\subsection{Kinetic Data}

The family of the kinetic curves for the series of isothermal runs with varying final reductions degree is presented on Fig. 5. Fairly good reproducibility of the data is seen in that figure. As was already said in Sec. 2.2 , the initial part of the kinetic curve was of accelerating type. This effect is not clearly seen on Fig. 5 because of overlapping of the curves. The initial parts of two curves are shown in the insert to Fig. 5.

For all curves the derivative plots $d R / d t v s$. time were made. The plots enable to estimate roughly the range of end of the accelerating part of the curves. The corresponding values of $R$ varied from 7 to $12 \%$. They are listed in Col. 3 of Table 6. For the final analysis of the kinetic data (Sec. 4.6) only the decelerating part of the kinetic curves was taken into account (run H-II is an exception) and this is why the initial part of curves has not been discussed at all.

\section{Discussion}

\subsection{On the Agreement between Porosimeter and Mi- croscopy Data}

The porosity data concerning the fully reduced sample are summarized in Table 4. The estimation of the total porosity by microscopy method was based on the same data as those used for calculation of the porosity profile. Each porosity value $P_{i}$ was multipled by the factor:

$$
f_{i}=\left\{\left[r_{\mathrm{m}}-(i-1) d\right]^{3}-\left(r_{\mathrm{m}}-i d\right)^{3}\right\} / r_{\mathrm{m}}^{3}
$$

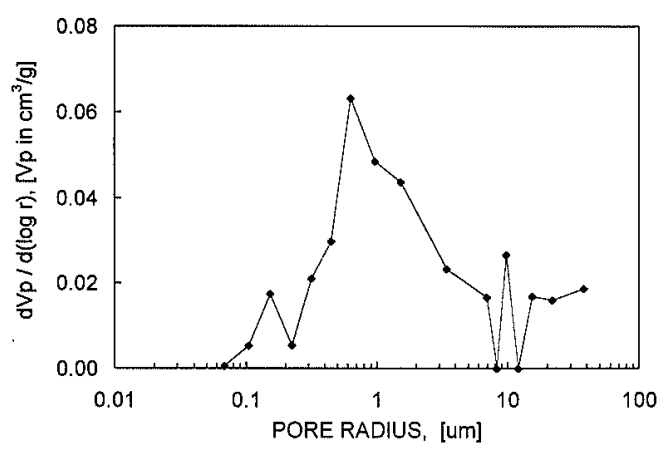

Fig. 4. Porosity spectrum of fully reduced hematite sample.

The total porosity (equal to $36.2 \%$; see Table 4 Col. 5) was calculated from the formula:

$$
P=\sum_{i=1}^{j} P_{i} f_{i}
$$

The definition and application of the factor $f_{i}$ is based on the assumption that the reduction progresses according to the ideal shrinking core-and-shell model.

Now, let us compare the porosity values obtained by both methods.

Only the pores of characteristic dimension greater than $0.6 \mu \mathrm{m}$ could be observed by microscopy method. The minimal value of pore radius amounts to $r=0.6 / 2 \sqrt{2} \approx$ $0.2 \mu \mathrm{m}$. The use of factor $\sqrt{2}$ is based on the very simple assumption that average angle between axes of randomly directed cylindrical pores and surface of the slice equals to $\left.45^{\circ} .12\right)$

The porosity related to pores of radii less than $30 \mu \mathrm{m}$ was measured by the mercury porosimetry. Figure 4 does not yield information concerning the pores of radii greater than $30 \mu \mathrm{m}$. The characteristic dimension for those pores amounts to $2 \cdot 30 \cdot \sqrt{2} \approx 85 \mu \mathrm{m}$. This is why the values of total porosity-as obtained by both methods (Table 4 Col. 5)-could not be compared directly. However, the comparison was possible when proper corrections were taken into account:

(1) the porosity related to pores of radii less than $0.2 \mu \mathrm{m}$ was determined directly from the porosimetric spectrum (Col, 2),

(2) on the microscopic picture the pores of characteristic dimension greater than $85 \mu \mathrm{m}$ were surrounded by handdrawn pencil line, and their total area was estimated planimetrically (Col. 4). Similarly, the area of whole grain picture was estimated too, and, hence, the porosity related to broad pores was calculated. 


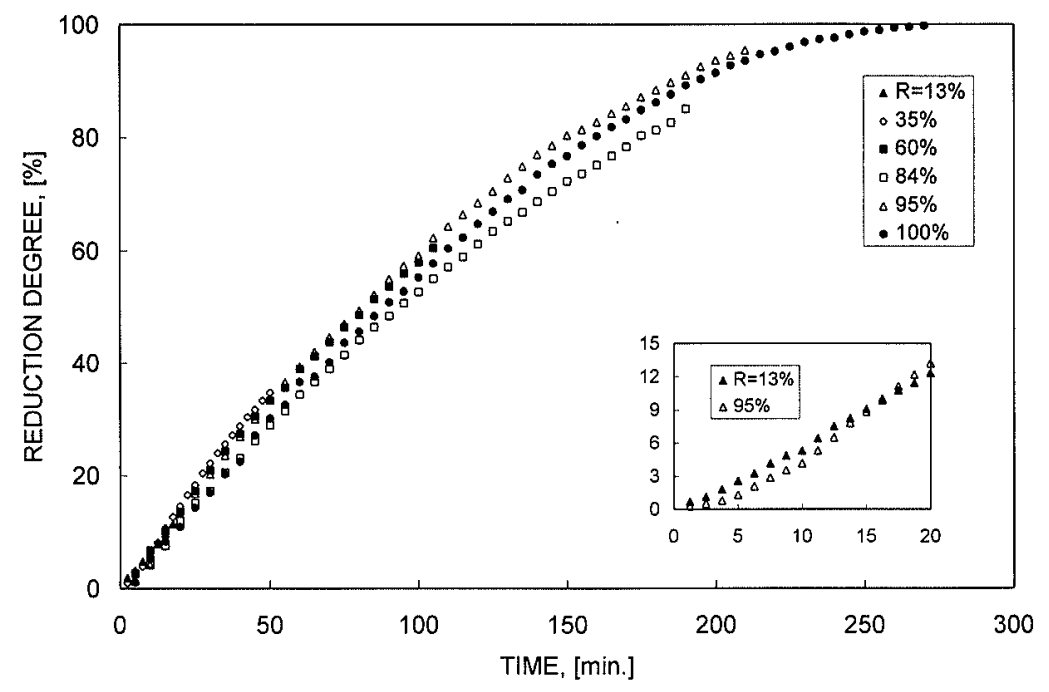

Fig. 5.

Kinetic curves of hematite to magnetite reduction. Values of the final reduction degrees are given in the figure.

Table 4. Porosity of the fully reduced sample H-VI.

\begin{tabular}{|c|c|c|c|c|}
\hline & \multicolumn{4}{|c|}{ Porosity [\%] } \\
\hline & measured & calculated & measured & measured \\
\hline 1 & 2 & 3 & 4 & 5 \\
\hline $\begin{array}{l}\text { Range of the pore } \\
\text { radii, }[\mu \mathrm{m}]\end{array}$ & $<0.2$ & $0.2-30$ & $>30$ & total porosity \\
\hline $\begin{array}{l}\text { Porosity determined } \\
\text { by Hg porosimetry }\end{array}$ & 1.6 & $24.1^{*}$ & undetectable & 25.7 \\
\hline $\begin{array}{l}\text { Porosity estimated } \\
\text { from microscopic } \\
\text { image }\end{array}$ & undetectable & $32.1^{*}$ & 4.1 & 36.2 \\
\hline
\end{tabular}

*calculated by difference

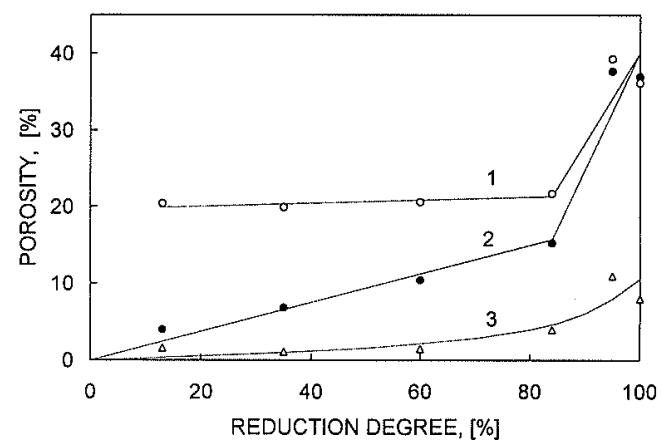

Fig. 6. Porosity as estimated from microscopy image: curve 1 - porosity of already reduced layer, 2 - porosity of total sample and 3 - porosity of large pores $(r>30 \mu \mathrm{m})$ arbitrarily defined as unmeasurable by mercury porosimetry.

Subtraction of both corrections from the total porosity values yields the data related to pore radii range between 0.2 and $30 \mu \mathrm{m}$ (Col. 3). Taking into account all uncertainties and simplifications (for example the closed pores are undetectable by porosimetry) - the values of 24.1 and $32.1 \%$ (Col. 3) seem to agree in a reasonable way.

\subsection{The Dependence of Porosity on the Reduction Degree}

The data of this type are shown in Fig. 6. It is clearly seen that when the progress of reduction is not greater than $80 \%$, the porosity of the reduced layer (Curve 1) remains constant, and, consequently, the porosity of total sample (Curve 2) increases proportionally to the reduction degree.

When the end of reduction is approaching ( $R=0.95$; $\left.d_{\text {mean }} / r_{\mathrm{m}}=0.6\right)$ there occurs a dramatic change in the texture of the sample-as directly seen on microphotographs (compare Figs. 2(a), (b), (c) and (d), (e), (f)) and evidenced by the sharp increase of all plots in Fig. 6 . The change may be caused by the increase of the amount of pores and the increase of their diameters. Crackling of magnetite during the final stage of reduction was noted in an earlier paper by Matyas and Bradshaw. ${ }^{5}$ Later the effect was explained by Ưnal and Bradshaw ${ }^{13)}$ by the action of mechanical strains related to the increase of the volume of hematite sample.

\subsection{The Change of the Sample Volume during the Reduction}

The crystallographic densities of hematite and magnetite are approximately equal. The unreduced sample is practically nonporous. It follows that the observed $36 \%$ increase of porosity implies the same increase of the volume of the reduced grain. Such volume increase is equivalent to $11 \%$ increase only of the dimension of the reduced grain.

Finally, let us note that the scattering of the dimensions listed in the second column of Table 2 amounts to $\pm 10 \%$. This is why in those studies the increase of the sample volume could not be taken into account as reliable source of information.

\subsection{Real and Model Topochemistry}

As was already said in Sec. 3.1, the microscopic pictures seen on Fig. 2 can be roughly approximated to shrinking core-and-shell model. It seems useful, however, to propose a quantitative measure of the discrepancy between the real behaviour and idealized model.

The scheme of idealized central cross section of a grain is presented on Fig. 7. The meaning of symbols $r_{0}$, $r_{\mathrm{c}}$ and $x$ follows directly from that Figure.

From obvious relation $r_{\mathrm{o}}=r_{\mathrm{c}}+x$ and definition of reduction degree $R=\left[(4 / 3) \pi r_{\mathrm{o}}^{3}-(4 / 3) \pi r_{\mathrm{c}}^{3}\right] /(4 / 3) \pi r_{\mathrm{o}}^{3}$ the following relation can be easily obtained

$$
x / r_{\mathrm{o}}=1-(1-R)^{1 / 3}=f(R)
$$




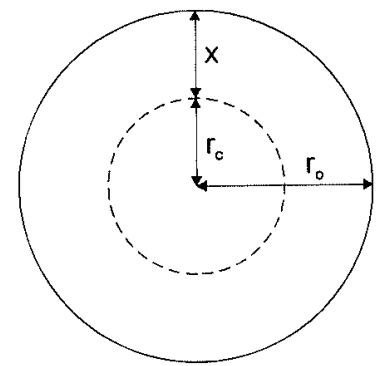

Fig. 7. Idealized central cross section of a hematite grain.

Table 5. Comparison between real and idealized topochemistry.

\begin{tabular}{|c|c|c|c|c|}
\hline Exp.No. & $\begin{array}{c}\text { Reduction } \\
\text { degree, [\%] }\end{array}$ & $\mathrm{d}_{\text {mean }} / \mathrm{r}_{\mathrm{m}}$ & $\mathrm{x} / \mathrm{r}_{0}=f(\mathrm{R})=\mathrm{l}-(\mathrm{l}-\mathrm{R})^{1 / 3}$ & $\mathrm{IND},[\%]$ \\
\hline $\mathrm{I}$ & 2 & 3 & 4 & 5 \\
\hline $\mathrm{H}-1$ & 13.2 & 0.069 & 0.046 & +49.9 \\
\hline H-II & 35.4 & 0.128 & 0.136 & -5.9 \\
\hline H-III & 60.3 & 0.202 & 0.265 & -23.8 \\
\hline H-IV & 84.0 & 0.323 & 0.543 & -40.5 \\
\hline H-V & 95.0 & 0.594 & 0.632 & -6.0 \\
\hline H-VI & 100 & 1 & 1 & - \\
\hline
\end{tabular}

The values of function $f(R)$ can be directly compared with microscopy data under the assumptions:

- the experimental value of reduction degree averaged for all grains can be also used for the characterization of a single grain,

- the ratio $x / r_{0}$ of the idealized model dimensions is equal to the dimensionless thickness of the reduced zone $d_{\text {mean }} / r_{\mathrm{m}}$.

The comparison between real and model topochemistry is given in Table 5. The Table contains:

- the values of dimensionless mean thickness of magnetite layer $d_{\text {mean }} / r_{\mathrm{m}}$ obtained from microscopy data (Col. 3),

- the values of model dimensionless thickness $f(R)=$ $1-(1-R)^{1 / 3}$ obtained solely from thermogravimetric data (Col. 4).

The discrepancy index (IND) (Col. 5) is defined as follows:

$$
\mathrm{IND}=\frac{\left[d_{\mathrm{mean}} / r_{\mathrm{m}}-f(R)\right]}{f(R)} \cdot 100 \%
$$

Let us compare now the values of IND with the shape of magnetite cores seen on Figs. 2(a)-2(e). The high absolute values of IND for experiments H-IV and H-III can be linked to the shape of core approximated to rectangular (2(d)) and irregular pentagon (2(c)), respectively. The low values of IND for experiments H-II and $\mathrm{H}-\mathrm{V}$ can be related to the shape of core revealing-to some extent-a curvature of core-shell interface. For more conclusive statements the more studied cases are needed.

\subsection{Kinetic Modelling}

Two kinetic models were applied in the present studies.

\subsubsection{Classical Shrinking Core Model}

This model is based-among others-on the assumption that the effective diffusivity is constant within the already reduced zone of the grain.

The model concerning mixed control formalism was clearly presented by Spitzer, Manning and Philbrook. ${ }^{14)}$ Diffusion of $\mathrm{CO}$ and $\mathrm{CO}_{2}$ in pores and reversible first order reaction at hematite/magnetite interface were assumed. In this paper gas film diffusion is neglected. From the equations 26 and 27 of paper ${ }^{14)}$ and the assumption that mass transfer coefficient approaches infinity the relations (6)-(9) can be easily obtained:

$$
\begin{array}{r}
t=M\left[1-(1-R)^{1 / 3}\right]+N\left[3-2 R-3(1-R)^{2 / 3}\right] \\
M=\frac{R_{\mathrm{g}} T c_{\mathrm{ox}} r_{\mathrm{k}}}{k_{\mathrm{r}}\left(p_{\mathrm{CO}}^{\mathrm{b}}-p_{\mathrm{CO}_{2}}^{\mathrm{b}} K_{\mathrm{e}}^{-1}\right)} \ldots \ldots \ldots \ldots \ldots \ldots \ldots \ldots \ldots \ldots \ldots \ldots \ldots \ldots
\end{array}
$$

Let us note that equilibrium constant $K_{\mathrm{e}}$ should be written for the stoichiometric equation indicating that only one mole of the reactant gas i.e. $\mathrm{CO}$ is consumed. The equation $3 \mathrm{Fe}_{2} \mathrm{O}_{3}+\mathrm{CO}=2 \mathrm{Fe}_{3} \mathrm{O}_{4}+\mathrm{CO}_{2}$ satisfies this condition.

Since in the present studies the exact separate determination of $D_{\mathrm{CO}}^{\text {eff }}$ and $D_{\mathrm{CO}_{2}}^{\text {eff }}$ was impossible, $\beta$ was treated as the parameter of the equation that characterizes the diffusion phenomena.

\subsubsection{Corrected Shrinking Core Model}

This model differs from the classical one by the assumption that the value of parameter $\beta$ varies continuously within the already reduced zone of the grain. The derivation of the basic equation is given below.

Taking into account the data from Table 3 one can write:

$$
P_{i}=H \exp \left(-G d_{i} / r_{\mathrm{m}}\right)
$$

where for the particular kinetic run $H$ and $G$ are the parameters of the Eq. (10).

Let us turn the attention to definition of $\beta$ (Eq. (9)). As both effective diffusivities cannot be determined separately let us assume that

$$
D_{\mathrm{CO}}^{\text {eff }}=\gamma D_{\mathrm{CO}_{2}}^{\text {eff }}
$$

where $\gamma$ is proportionality factor.

Finally, let us write the fundamental relationship ${ }^{15)}$ for the case of carbon monoxide diffusion:

$$
D_{\mathrm{CO}}^{\text {eff }}=D_{\mathrm{CO}}^{\mathrm{c}} P_{i} \tau^{-1}
$$

where $\tau$ is the tortuosity factor and $D_{\mathrm{CO}}^{\mathrm{c}}$ is the combined diffusivity that takes into account both molecular as well as Knudsen diffusion. Let us assume that $D_{\text {co }}^{\mathrm{c}}$ is roughly constant during a particular kinetic run; it means that the pore distribution does not depend significantly on the reduction degree.

Subștitution of Eqs. (10)-(12) into Eq. (9) yields: 


$$
\beta=\frac{D_{\mathrm{CO}}^{\mathrm{c}} H K_{\mathrm{c}}}{\tau\left(\gamma+K_{\mathrm{e}}\right)} \exp \left(-G d_{i} / r_{\mathrm{m}}\right)
$$

Let us assume that:

(1) the value $\beta_{\mathrm{o}}=D_{\mathrm{CO}}^{\mathrm{c}} H K_{\mathrm{e}} / \tau\left(\gamma+K_{\mathrm{e}}\right)$ is constant for a particular kinetic run,

(2) the ratio $d_{i} / r_{\mathrm{m}}$ can be approximated by $x / r_{0}$ and $r_{\mathrm{o}}$ can be approximated by $r_{\mathrm{k}}$,

(3) the empirical parameter $G$ can be replaced by adjustable kinetic parameter $g$,

(4) all uncertainties and simplifications introduced in this derivation make such modified parameter $\beta$ different from the original one. This is why $\beta$ was replaced by $\beta_{\text {corr: }}$ :

$$
\beta_{\text {corr }}=\beta_{0} \exp \left[-g\left(x / r_{\mathrm{k}}\right)\right]
$$

Let us further assume that for a certain value of $\left(x / r_{\mathrm{k}}\right)^{*}$ inside the reduced zone of the grain $\beta_{\text {corr }}=\beta$, where $\beta$ is calculated from classical SCM by two parameter minimization procedure. Hence:

$$
\beta=\beta_{0} \exp \left[-g\left(x / r_{\mathrm{k}}\right)^{*}\right]
$$

Equations (14) and (15) are divided by sides and the final relation is obtained:

$$
\beta_{\text {corr }}=\beta \exp \left\{g\left[\left(x / r_{\mathrm{k}}\right)^{*}-\left(x / r_{\mathrm{k}}\right)\right]\right\}
$$

It is seen from Eq. (16) that the exponent term is the correction imposed by the proposed model on the value of $\beta$ calculated from the classical relation (9).

Dimensionless distance $\left(x / r_{\mathrm{k}}\right)^{*}$ is the adjustable parameter of the kinetic equation. Its value should be positive and smaller than the thickness of the reduced layer available from microscopy as well as from kinetic data. Taking into account experimental errors and all introduced uncertainties and simplifications the parameter $g$ is treated as the adjustable parameter too. It is expected, however, that its value will be close to the exponent constant of the porosity profile (see Table 3 ).

Let us note that for points which are very close to the surface of the grain $\left(x / r_{\mathrm{k}}\right)^{*}>\left(x / r_{\mathrm{k}}\right)$ and $\beta_{\mathrm{corr}}>\beta$. Hence the corrected SCM tells us that at the beginning of the kinetic run the diffusion phenomena play a less significant role than expected from classical SCM. For the points that are very close to magnetite-hematite interface

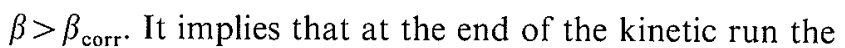
opposite statement is true.

\subsection{Applicability of the Kinetic Models to the Ex- perimental Data}

The most essential results are summarized in Tables 6 and 7 .

\subsubsection{The Classical Shrinking Core Model}

As shown in Appendix 1 the 'reasonable' value of $\beta$ amounts to $0.11 \mathrm{~cm}^{2} \cdot \mathrm{s}^{-1}$.

As evidenced by the data from Table 6 Col. 9 with the exception of exp. H-II all values of $\beta$ calculated for full range of $R$ (Col. 2) have unreasonable high values $10^{2}-10^{5} \mathrm{~cm}^{2} \cdot \mathrm{s}^{-1}$ and therefore they are lacking physicochemical meaning.

In this situation the properly selected part of the kinetic curve was only considered in order to find a reasonable value of $\beta$ in a forcefully imposed way. It was always possible to find the limited and optimal range of reduction degree (Col. 4) for which $\beta$ has a reasonable value (Col. 7). The method of the rejection of the beginning of the kinetic curve ${ }^{16)}$ was helpful in these types of calculations.

Let us note that CSM implies the decelerating type of kinetic curve. Hence the initial accelerating type of kinetic curve has to be neglected. For runs H-I, H-III, H-IV and $\mathrm{H}-\mathrm{V}$ the beginning of the optimal range of validity of CSM (Col. 4) agrees in a reasonable way with the end of accelerating range mentioned in Sec. 3.3 (see Col. 3). For run H-VI the value $d R / d t$ is nearly constant within the range of $R$ from 8 to $28 \%$. The optimal range amounts to $40-70 \%$. Run H-II is untipical for the unknown reasons and in all kinetic calculations was considered as an exception. The rejection of the final part of the kinetic curve is justified in not so convicting way. However, the dramatic changes of the texture as discussed in Sec. 4.2 are worthwhile mentioning.

Both value of $\beta$ calculated for narrowed and full range of $R$ are compared with value of $\beta \approx 0.11 \mathrm{~cm}^{2} \cdot \mathrm{s}^{-1}$ estimated on the basis of porosity data for fully reduced sample (Col. 8 and 10 of Table 6, respectively). Undoubtedly the values of $\beta$ for narrowed range are far more reliable. Let us also note that assumptions mentioned in Appendix 1 indicate that the value of

Table 6. Data related to classical shrinking core model.

\begin{tabular}{|c|c|c|c|c|c|c|c|c|c|}
\hline \multirow{2}{*}{ Exp.No. } & $\begin{array}{c}\text { Full range } \\
\text { of } \mathrm{R}\end{array}$ & $\begin{array}{c}\text { End of accele- } \\
\text { rating period }\end{array}$ & $\begin{array}{c}\text { Optimal } \\
\text { range of } \mathrm{R}\end{array}$ & \multicolumn{3}{|c|}{ Data related to optimal range of $\mathrm{R}$} & \multicolumn{2}{|c|}{$\begin{array}{c}\text { Data related to full } \\
\text { range of } \mathrm{R}\end{array}$} \\
\cline { 2 - 11 } & $\%$ & $\%$ & $\%$ & st. dev., $\%$ & $\mathbf{k}_{\mathrm{r},} \mathrm{cm}^{-1}$ & $\beta, \mathrm{cm}^{2} \mathrm{~s}^{-1}$ & $0.11 / \beta$ & $\beta, \mathrm{cm}^{2} \cdot \mathrm{s}^{-1}$ & $\beta / 0.11$ \\
\hline $\mathrm{H}$ & 2 & 3 & 4 & 5 & 6 & 7 & 8 & 9 & 10 \\
\hline $\mathrm{H}-\mathrm{I}$ & $0 \div 13$ & $6 \div 8$ & $7 \div 13$ & 0.09 & 0.122 & $3.51 \mathrm{E}-3$ & 31 & $2.12 \mathrm{E}+2 *$ & $1.9 \mathrm{E}+3$ \\
\hline $\mathrm{H}-\mathrm{II}$ & $0 \div 35^{* *}$ & $6 \div 9$ & $3 \div 35$ & 0.12 & 0.148 & $3.63 \mathrm{E}-3$ & 30 & $3.63 \mathrm{E}-3$ & $3.3 \mathrm{E}-2$ \\
\hline $\mathrm{H}-\mathrm{IV}$ & $0 \div 60$ & $7 \div 12$ & $10 \div 57$ & 0.23 & 0.110 & $1.73 \mathrm{E}-2$ & 6 & $8.00 \mathrm{E}+4 *$ & $7.3 \mathrm{E}+5$ \\
\hline $\mathrm{H}-\mathrm{V}$ & $0 \div 84$ & $10 \div 11$ & $17 \div 54$ & 0.23 & 0.110 & $1.48 \mathrm{E}-2$ & 7 & $4.99 \mathrm{E}+5 *$ & $4.5 \mathrm{E}+6$ \\
\hline $\mathrm{H}-\mathrm{VI}$ & $0 \div 100$ & $7 \div 10$ & $40 \div 70$ & 0.15 & 0.137 & $2.48 \mathrm{E}-2$ & 4 & $4.87 \mathrm{E}+5 *$ & $4.4 \mathrm{E}+6$ \\
\hline
\end{tabular}

* unreasonable value of parameters

** experimental uncertainity for $\mathrm{R}<3 \%$ 
ISIJ International, Vol. 36 (1996), No. 3

Table 7. Data related to corrected shrinking core model.

\begin{tabular}{|c|c|c|c|c|c|c|c|c|c|}
\hline \multirow{2}{*}{ Exp.No. } & \multirow{2}{*}{$\begin{array}{c}\begin{array}{c}\text { Full range } \\
\text { of } \mathrm{R}\end{array} \\
\%\end{array}$} & \multicolumn{5}{|c|}{ Data related to corrected SCM } & \multirow{2}{*}{$\begin{array}{c}\begin{array}{c}\text { Maximal } \\
\text { layer } \\
\text { thickness }\end{array} \\
\mathrm{d}_{\max } / \mathrm{r}_{\mathrm{m}}\end{array}$} & \multirow{2}{*}{$\begin{array}{c}\begin{array}{c}\text { Porosity } \\
\text { profile } \\
\text { parameter }\end{array} \\
G\end{array}$} & \multirow{2}{*}{$\begin{array}{l}\begin{array}{c}\text { Optimal range } \\
\text { for corrected } \\
\text { SCM }\end{array} \\
\%\end{array}$} \\
\hline & & $\beta, \mathrm{cm}^{2} \mathrm{~s}^{-1}$ & $\left(\mathrm{x} / \mathbf{r}_{\mathrm{k}}\right)^{*}$ & $\mathbf{k}, \mathrm{cm}, \mathrm{s}^{-1}$ & g & st.dev., \% & & & \\
\hline 1 & 2 & 3 & 4 & 5 & 6 & 7 & 8 & 9 & 10 \\
\hline $\mathrm{H}-\mathrm{I}$ & $0 \div 13$ & $3.51 \mathrm{E}-3$ & $\begin{array}{l}0.0538 \\
0.0346 \\
\end{array}$ & $\begin{array}{l}0.0628 \\
0.0407\end{array}$ & $\begin{array}{l}23.782 \\
26.907 \\
\end{array}$ & $\begin{array}{l}0.58 \\
0.98\end{array}$ & 0.078 & 23.8 & $7 \div 13$ \\
\hline H-II & $0 \div 35$ & $3.63 \mathrm{E}-3$ & 0.138 & 0.141 & 9.265 & 0.42 & 0.142 & 16.9 & $3 \div 35^{* *}$ \\
\hline H-III & $0 \div 60$ & $1.73 \mathrm{E}-2$ & $\begin{array}{l}0.200 \\
0.145 \\
\end{array}$ & $\begin{array}{l}0.109 \\
0.117 \\
\end{array}$ & $\begin{array}{c}2.54 \mathrm{E}-5^{*} \\
2.127\end{array}$ & $\begin{array}{l}0.58 \\
0.16 \\
\end{array}$ & 0.227 & 8.65 & $8 \div 50$ \\
\hline $\mathrm{H}-\mathrm{IV}$ & $0 \div 84$ & $1.48 \mathrm{E}-2$ & $\begin{array}{l}0.931 * \\
0.291\end{array}$ & $\begin{array}{l}0.090 \\
0.100\end{array}$ & $\begin{array}{l}1.265 \\
2.249\end{array}$ & $\begin{array}{l}2.60 \\
0.52\end{array}$ & 0.362 & 5.25 & $17 \div 51$ \\
\hline $\mathrm{H}-\mathrm{V}$ & $0 \div 95$ & $2.18 \mathrm{E}-2$ & $\begin{array}{c}0.803^{*} \\
0.591\end{array}$ & $\begin{array}{l}0.119 \\
0.120\end{array}$ & $\begin{array}{l}0.326 \\
0.694\end{array}$ & $\begin{array}{l}1.09 \\
0.58\end{array}$ & 0.669 & 0.711 & $8 \div 70$ \\
\hline $\mathrm{H}-\mathrm{VI}$ & $0 \div 100$ & $2.48 \mathrm{E}-2$ & $\begin{array}{l}0.559 \\
0.599\end{array}$ & $\begin{array}{l}0.114 \\
0.144\end{array}$ & $\begin{array}{l}0.517 \\
0.514\end{array}$ & $\begin{array}{l}4.52 \\
0.65\end{array}$ & 1.00 & 0.514 & $40 \div 78$ \\
\hline
\end{tabular}

* unreasonable value of parameters

** experimental uncertainity for $\mathrm{R}<3 \%$

$0.11 \mathrm{~cm}^{2} \cdot \mathrm{s}^{-1}$ is the upper limit of the effective diffusivity. The value of tortuosity factor let us say $\tau=3$ is also permissible. Additionally, the porosity data were taken for fully reduced sample. As seen from Fig. 6 samples reduced up to $80 \%$ shown smaller values of porosity.

In the conclusion one can say that the validity of SCM in the narrowed range of $R$ is significant more certain and the values of $\beta$ are far more reliable. This is why these values have been taken for the calculations concerning the corrected model.

\subsubsection{The Corrected Shrinking Core Model}

The reasonable values of $\beta$ are rewritten in Table 7 Col. 3. They were used for calculation of parameters of the model for full range of $R$. The values of three parameters $\left(x / r_{\mathrm{k}}\right)^{*}, k$ and $g$ are given in upper positions of Col. 4-6. The reliability of these values were examined. In two cases (exp. H-IV and H-V) the values of $\left(x / r_{\mathrm{k}}\right)^{*}$ were greater than layer thickness (Col. 8). In one case (exp. H-III) the value of parameter $g$ (Col. 6) differs drastically from the value of parameter $G$ rewritten in Col. 9 from Table 3. However, for the narrowed range of $R$ (compare Col. 10 and Col. 2) all parameters (given in lower position of Col. 4-6) have reasonable values.

\subsubsection{Comparison of the Models}

The average values of $k_{\mathrm{r}}$ and $k$ amount to $0.124 \pm 0.015$ and $0.110 \pm 0.027 \mathrm{~cm} \cdot \mathrm{s}^{-1}$ for classical and corrected SCM respectively. These values are in a reasonable agreement with the data calculated from literature equations as shown in Table 8.

By comparison of Col. 4 of Table 6 and Col. 10 of Table 7 one can easily see that the corrected model is valid in the slightly broader range of reduction degree. By comparing Col. 5 of Table 6 and Col. 7 of Table 7 it is obvious that the fitness of the corrected model is significantly worse as indicated by greater values of the respective standard deviations. This result is an unexpected one. The reader is reminded that the derivation of the corrected model was based on the
Table 8. Values of rate constant for hematite to magnetite reduction at $850^{\circ} \mathrm{C}$.

\begin{tabular}{|l|c|c|c|}
\hline \multicolumn{1}{|c|}{ Equation } & $\mathrm{k}_{\mathrm{r}}\left[\mathrm{cm} \mathrm{s}^{-1}\right]$ & Reference & Remarks \\
\hline \multicolumn{1}{c}{$\mathrm{I}$} & 2 & 3 & 4 \\
\hline$\Phi=69 \exp (-8950 / \mathrm{T})$ & 0.2 & $9)$ & $\mathrm{a}$ \\
\hline$\Phi=7.75 \cdot 10^{-2} \exp (-4100 / \mathrm{T})$ & 0.02 & $20)$ & $\mathrm{a}, \mathrm{c}$ \\
\hline$\Phi=10^{-4.40} \exp (-12450 / \mathrm{T})$ & 3.5 & $18)$ & $\mathrm{a}$ \\
\hline $\mathrm{k}_{\mathrm{r}}=\exp \left(5.57-1.25 \cdot 10^{4} / \mathrm{RT}\right)$ & 1.0 & $19)$ & $\mathrm{b}$ \\
\hline
\end{tabular}

a) $k_{\mathrm{r}}\left[\mathrm{cm} \mathrm{s}^{-1}\right]=\Phi\left[\mathrm{mol} \mathrm{m}^{-2} \mathrm{~s}^{-1} \mathrm{~atm}^{-1}\right] \cdot \mathrm{RT}$, see ref. 14) $\mathrm{R}=82.06 \mathrm{~cm}^{3} \mathrm{~atm} \mathrm{m^{-1 }} \mathrm{K}^{-1}$

b) $\mathrm{R}=1.987 \mathrm{cal} \mathrm{mol}^{-1} \mathrm{~K}^{-1}$

c) taken from ref. 9 )

additional reliable experimental data (see Table 3) and that the additional adjustable parameter $g$ was introduced to the corrected SCM. In order to explain the above nonunderstandable facts an additional unknown and significant effect should be taken into account. Very nice agreement of the values of rate constants should be once more emphasized. In this situation the effect in question has to be related to the pore diffusion phenomena. Finally, it is worthwhile mentioning that the description of reduction of iron catalyst by SCM became also slightly worse when the variation of effective diffusivity with reduction degree was taken into account. ${ }^{17)}$

\subsection{Kinetic Curves of Pore Formation}

In general case the effective diffusivity may vary with space and time. The variation with space - within the reduced part of a grain - was already discussed in the previous section. The concept of variation with timewithin the time interval equal to duration of kinetic experiment-was lacking. Let us discuss this effect taking into account the data available in this paper.

A number of points of equal dimensionless distance from the external surface of grain were chosen within the range from zero to 0.3 . This highest value corresponds to the reduction degree $c a$. $65 \%$. For this series of 


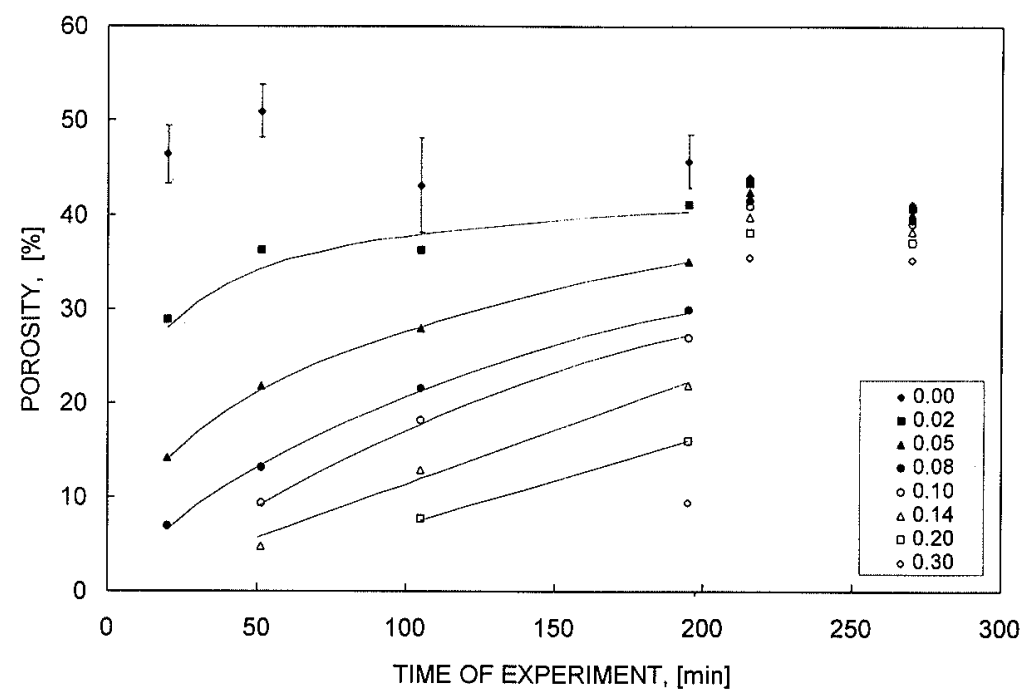

Fig. 8.

Evolution of the local porosity upon time. Chosen values of dimensionless distance $d_{i} / r_{\mathrm{m}}$ are given directly on the figure. distances the value of local porosity were calculated from equations listed in Col. 4 of Table 3. The values of local porosity at sample surface i.e. for $d_{i} / r_{\mathrm{m}}=0$ are of course equal to preexponential terms. Let us note that the time allowed to formation of pores within the particular grain - as seen on Fig. 2-is equal to time needed to obtain its final reduction degree. This is why the chosen values of local porosity were plotted versus final reduction times taken from appropriate curves seen on Fig. 5. The plots thus obtained, seen on Fig. 8, visualize the evolution of the local porosity with time. The plots form a family of smooth curves. The points for times greater than 200 min corresponding to reduction degrees 95 and $100 \%$ were not taken into account. It was already said in Sec. 4.2 that the untypical effects are observed during the final stage of hematite/magnetite reduction.

As seen from Fig. 8 the porosity increases with time. This effect is more significant in the deeper part of the grain. Let us note that in principle, by an interpolation, it is possible to estimate the local porosity in each time and in each point within the indicated range of the dimensionless distance from the external surface of the grain. However, in this paper such data would be uncertain because the curves seen on Fig. 8 in the most favourable cases are based on four points only.

\section{Concluding Remarks and Research Prospects}

In this paper the variation of local porosity with the grain radius of the reduced iron oxide was determined in a reliable way whereas its variation with reduction time was estimated in semiquantitative way only.

The spatial dependence was introduced to the corrected SCM. There is obvious need to take into account also the time dependence. The first step for creation of this postulated and new model is to find equations that will describe the evolution of local porosity in time as seen on Fig. 8. For collecting the variety of experimental data needed for this purpose the more advanced methods of image analysis are, of course, required. The determination of pore distribution for broad range of final reduction degree would be of course beneficial also.

From this paper point of view the classical SCM with the assumed single value of porosity is the model of empirical type only. However, the averaging of the local porosity upon space and time yields remarkably good results as evidenced by numerous papers. $\left.{ }^{9}, 18-20\right)$ The case when the empirical relation fits experimental data better than the equation with the physicochemical meaning was discussed by Pearson. ${ }^{21)}$

Finally, let us try to explain the genesis of porosity profile. Temperature chosen in this studies (similarly to papers ${ }^{8,9,19)}$ ), sharp hematite-magnetite interface seen on Fig. 2 and lack of hematite inside the shell strongly support core- and shell model. It seems therefore unlikely that the increase of porosity inside the shell observed on Fig. 8 is caused directly by the removal of oxygen from solid. Perhaps the oxygen lost is accompanied by simultaneous formation of very fine micropores invisible in this studies. Consecutively, the visible pores are formed due to a coalescence and/or a sintering process. ${ }^{13,22)}$ High value of porosity for the sample reduced to 95 and $100 \%$ are in favour for the above stated tentative hypothesis concerning time lag necessary to pore formation. Undoubtedly further studies are needed in order to clear the matter.

\section{Acknowledgements}

This work was sponsored by The Polish State Committee for the Scientific Research under Grant No. 336039102 in the years 1992-1995. Authors are grateful to Professor J. Bodziony, Mrs. T. Ratajczak and Mr. M. Młynarczuk at Strata Mechanics Research Institute, Polish Academy of Science, Cracow, Poland, for their interest and practical assistance as well as to dr. J. M. Łagan for computer calculations.

\section{Nomenclature}

$c_{\mathrm{ox}}$ : concentration of removable oxygen in the hematite grain $\left(\mathrm{mol} \mathrm{cm}^{-3}\right)$

$d:$ slice thickness $(\mu \mathrm{m})$

$d_{i}$ : thickness of magnetite layer consisting of $i$ slices $d_{i}=i \cdot d(\mu \mathrm{m})$

$d_{\min }$ : thickness of magnetite layer for final reduction degree taken for the minimal amount of slices in the investigated layer 
$(\mu \mathrm{m})$

$d_{\text {mean }}: \quad i b i d$. for the mean amount of slices $(\mu \mathrm{m})$

$d_{\max }: \quad$ ibid. for the maximal amount of slices $(\mu \mathrm{m})$

$D_{\mathrm{Co}}^{\mathrm{c}}$ : combined diffusivity of $\mathrm{CO}\left(\mathrm{cm}^{2} \mathrm{~s}^{-1}\right)$

$D_{\mathrm{CO}}^{\text {eff }}, D_{\mathrm{CO}_{2}}^{\text {eff }}$ : effective diffusivity coefficient of $\mathrm{CO}$ or $\mathrm{CO}_{2}\left(\mathrm{~cm}^{2} \mathrm{~s}^{-1}\right)$

$f_{i}$ : factor defined by Eq. (2) (see Sec. 4.1)

$g$ : parameter of the Eq. (14)

$G, H:$ parameters of the empirical Eq. (10)

$i$ : slice number

IND: discrepancy index, defined by Eq. (5) (see Sec. 4.4)

$j$ : maximal slice number in the given zone

$k_{\mathrm{r}}$ : rate constant for classical $\mathrm{SCM}\left(\mathrm{cm} \mathrm{s}^{-1}\right)$

$k$ : rate constant for corrected $\mathrm{SCM}\left(\mathrm{cm} \mathrm{s}^{-1}\right)$

$K_{\mathrm{e}}$ : equilibrium constant of reaction $3 \mathrm{Fe}_{2} \mathrm{O}_{3}+$ $\mathrm{CO}=2 \mathrm{Fe}_{3} \mathrm{O}_{4}+\mathrm{CO}_{2}$

$M, N$ : parameters of the kinetic equation (see Eqs. (6), (7) and (8))

$P_{\mathrm{CO}}^{\mathrm{b}}, p_{\mathrm{CO}_{2}}^{\mathrm{b}}: \quad$ pressure of $\mathrm{CO}$ or $\mathrm{CO}_{2}$ in the bulk of gas phase (atm)

$P_{i}: \quad$ porosity of slice $i(\%)$

$P: \quad$ total porosity of reduced layer $(\%)$

$r:$ radius of pore calculated from porosimetric data $(\mu \mathrm{m})$

$r_{\mathrm{k}}$ : radius of unreduced grain (see Sec. 2.2) $(\mu \mathrm{m})$

$r_{\mathrm{m}}$ : radius of reduced grain, calculated from microscopy observations (see Sec. 2.3) $(\mu \mathrm{m})$

$r_{0}: \quad$ radius of idealized spherical grain (a.u. $)^{* *}$

$r_{\mathrm{c}}$ : radius of core of idealized partly reduced grain (a.u.)**

$R: \quad$ reduction degree $(\%)$

$R_{\mathrm{g}}$ : gas constant $\left(\mathrm{cm}^{3}\right.$ atm $\left.\mathrm{mol}^{-1} \mathrm{~K}^{-1}\right)$ or (cal mol ${ }^{-1} \mathrm{~K}^{-1}$ )

$t:$ time (s)

$T:$ absolute temperature $(\mathrm{K})$

$V_{\mathrm{p}}:$ specific pore volume $\left(\mathrm{cm}^{3} \mathrm{~g}^{-1}\right)$

$x$ : thickness of shell of idealized spherical grain (a.u.)**

$\beta$ : parameteer of Eq. (6) (the case of classical CSM) defined by Eqs. (8) and (9) $\left(\mathrm{cm}^{2} \mathrm{~s}^{-1}\right)$

$\beta_{\text {corr }}$ : parameter of Eq. (6) (the case of corrected CSM) defined by Eq. (14) $\left(\mathrm{cm}^{2} \mathrm{~s}^{-1}\right)$

$\beta_{0}$ : preexponential factor in Eq. (14) $\left(\mathrm{cm}^{2} \mathrm{~s}^{-1}\right)$

$\Phi$ : rate constant $\left(\mathrm{mol} \mathrm{m}^{-2} \mathrm{~s}^{-1} \mathrm{~atm}^{-1}\right)$

$\tau$ : tortuosity factor

$d_{i} / r_{\mathrm{m}}$ : dimensionless thickness of magnetite layer consisting of $i$ slices

$\left(d_{i} / r_{\mathrm{m}}\right)^{*}$ : the specific value of $d_{i} / r_{\mathrm{m}}$ implying by definition the equality $\beta=\beta_{\text {cor }}$

**: arbitrary unit under the condition that the same unit is used for $r_{0}, r_{\mathrm{c}}$ and $x$

\section{REFERENCES}

1) J. Szekely, J. W. Ewans and H. Y. Sohn: Gas-Solid Reactions, Academic Press, New York-San Francisco-London, (1976), 5.

2) W. Katscher, W. Delle, H.-K. Hinssen, R. Moormann and E. Wallura: Beiträge zur 3 Intern. Kohlenstofftagung Carbon ' 80 , June 30-July 4 1980, Baden-Baden, Kernforschungsanlage Julich GmbH, Jul-Conf-36, 18.

3) J. Szekely, J. W. Ewans and H. Y. Sohn: Gas-Solid Reactions, Adademic Press, New York-San Francisco-London, (1976), 156.

4) M. Ishida and C. Y. Wen: AIChEJ, 14 (1968), 311.

5) A. G. Matyas and A. V. Bradshaw: Ironmaking Steelmaking, 3 (1974), 180.

6) J. Y. Park and O. Levenspiel: Chem. Eng. Sci., 30 (1975), 1207.

7) A. Barański, A. Kotarba, J. M. Łagan, A. Pattek-Janczyk, E. Pyrczak and A. Riezer: Appl. Catal. A, General, 112 (1994), 13.

8) C. Gleitzer: Solid State Ionics, 38 (1990), 133.

9) M. Ettabirou, B. Dupre and C. Gleitzer: Metall. Trans. B, 19B (1988), 311.

10) J. Janowski, M. Wyderko-Delekta, A. Sadowski and J. Delekta: Steel Res., 66 (1995), 135

11) M. Ohmi, T. Usui, M. Naito and Y. Minamide: Trans. Iron Steel Inst. Jpn., 23 (1983), 81.

12) A. Wheeler: Catalysis, ed. by P. H. Emmett, Reinhold Publ. Co., New York, (1961), Vol. II, 105 (see p. 124).

13) A. Ünal and A. V. Bradshaw: Metall. Trans. B, 14B (1983), 743.

14) R. H. Spitzer, F. S. Manning and W. O. Philbrook: Trans. Metall. Soc. AIME, 236 (1966), 726.

15) Ch. G. Hill, Jr.: An Introduction to Chemical Engineering Kinetics and Reactor Design, Villey and Sons, New York-ChichesterToronto, (1977), 435.

16) J. Janowski, A. Barański, J. M. Lagan, J. Nedoma, and A. Sadowski: Reactiv. Solids, 1 (1986), 297.

17) A. Barański, J. M. Lagan, A. Pattek and A. Riezer: React. Kinet. Catal. Lett., 15 (1980), 285.

18) P. C. Hayes: Metall. Trnas. B., 10B (1979), 211.

19) T. Usui, M. Ohmi, S. Kaneda, M. Ohmosa and Z. Morita: ISIJ Int., 31 (1991), 425.

20) J. J. Heizmann, P. Becker and R. Baro: Arch. Eisenhïttenwes., 45 (1974), 765.

21) R. G. Pearson: J. Phys. Chem., 81 (1977), 2323.

22) H. Brill-Edwards, B. L. Daniell and R. L. Samuel: J. Iron Steel Inst., 203 (1965), 361.

23) A. V. Bradshaw and A. G. Matyas: Metall. Trans. B, 7 B (1976) 81 .

\section{Appendix 1. Estimation of the Value of Parameter $\beta$}

Equilibrium constant for hematite/magnetite reduction by $\mathrm{CO}$ is of order $10^{4}-10^{5} .{ }^{23)}$ Hence the definition (9) and relation (12) yields:

$$
\beta=D_{\mathrm{CO}}^{\mathrm{eff}}=D_{\mathrm{CO}}^{\mathrm{c}} \cdot P \cdot \tau^{-1}
$$

Calculation of $D_{\text {CO }}^{\text {eff }}$ was similar to the method described in. $^{23)}$ In order to estimate Knudsen diffusion coefficient the pore spectrum from Fig. 4 was divided into 17 slices, each slice being characterized by one averaged value of pore radius only. Effective diffusivity was calculated for each slice and the value of $\beta$ was obtained directly by addition. Single value of tortuosity factor $(\tau=2)$ was assumed. The estimated value of $\beta$ amounts to $0.11 \mathrm{~cm}^{2} \mathrm{~s}^{-1}$. 